\title{
Research on the Use of Mobile Learning to Teach English
}

\author{
Jie XIONG \\ School of Foreign Languages \\ Jiujiang University \\ Jiujiang,Jiangxi,China
}

\begin{abstract}
The University proposed the concept of mobile learning. English has laid a solid foundation for the creation of mobile learning mode. Mobile learning mode is to promote college English teaching reform actively trying. Mobile learning mode provides a platform for independent learning. This paper attempts to survey the current college English learners' views and understanding of mobile learning, learners find their own problems, which made constructive suggestions in order to promote college English mobile learning mode to achieve tangible results.
\end{abstract}

Keywords- mobile learning; reform; phone learning

\section{INTRODUCTION}

The existing mobile learning mainly relies on the phone. A survey conducted in 2009 showed that "In the handheld terminal, the phone is the closest one-hand-holding media college students carry, where its use to cover the entire campus life." Discovery made in 2012 in tune" mobile dictionary shares much more than handheld electronic dictionaries, dictionaries, as a rising star of the mobile phone, has become the main force in the electronic dictionary." Mobile Dictionary using provided support for mobile learning, learning software downloaded through the network is currently one of the main ways students achieve mobile learning. Students are in contact with the learning task, it has been held by certain ideas that students use them to guide their language learning. Students' learning concepts and ideas will enhance teachers' understanding of the students, and ultimately improve the effectiveness of teaching and learning. Whether it is for language learning or for foreign language teaching, research ideas learner plays a vital role. Then, as a popular mode of learning, which students accept and apply to mobile learning? Are they the learners to achieve self-learning through mobile learning mode? That's what this article is to explore.

\section{RESEARCH OF MOBILE ENGLISH LEARNING}

Currently, lifelong education and education for all has become a hot modern society, the traditional way of learning can no longer meet the learning needs of the people all the time. Meanwhile, with the maturing of the mobile terminal and other functional mobile computer devices, and it is currently being applied to the modern communication services. Third generation mobile communication technology (3rd-generation, 3G) technology has become more sophisticated, mobile learning is becoming the research hotshot. The introduction of mobile learning to college students has become a necessary means. Mobile learning platform should provide at least learning resources and learning services. Learning resources include learning content, learning materials and targeted test questions; learning services include learning progress of management, learning and evaluation. Accordingly, we proposed design objectives and principles of the system.

\section{A. Designing Goals}

Combined with design ideas and college students, to learn the actual situation of the system's design goals can be summarized as follows. Considering individual preferences, time and other factors, to achieve the learner at any time and place, we can use the system for low-cost and efficient but also situational learning. On the content of learning, we can provide individualized learning content and learning resources to complete individualized teaching process, to meet the needs of different levels of levels of learners. Taking the interaction into account, we can provide convenient self-test means to achieve the evaluation of teaching effectiveness. We can provide the basis for continued learning. At present, the common learning platform has colorful and complex function. The development of this system has a certain reference. Considering mobile learning system developed by the actual situation, the system design goals were further optimized. As for the target function, this goal has been to meet the needs of mobile learning.

\section{B. Design Principles}

Starting from the system's design goals, with the current technology has matured. The system should be designed to determine the following principles.

Cheap cost. At present, the reality that the cost of mobile learning to communicate is expensive cannot be solved in the short term. The system must be based on the content concise. We should download speed design principles. In order to reduce communication costs, it can be taken online learning and offline learning combined with effective communication process text compression techniques.

Practicality. For university English study, the system should be based on Department of Higher Education in 2007 promulgated the "College English Curriculum Requirements", it should also be in close connection with the 
college English class at the same time and expand the classroom for the design principles.

Interactivity. Interactivity is embodied in humancomputer dialogue system. While the interactive learning process can effectively improve the efficiency of learning, create realistic learning situations and mobilize learners' creativity.

Individuation. Differences between individuals result in different individual learning abilities. The system must contain the learning content management to personalize learning progress organizing principle. Especially for the English word learning and memory ability. Learners directly led to different learning efficiency. According to the laws of individual memory, organizational learning content, learning progress control becomes very important.

\section{COllege English TeACHING PRACTICE OF Collaborative Mobile LeARNING MODE}

Using mobile phones or other mobile devices can learn more liberal than learning in the traditional sense, it has certain advantages, but the students' self-learning ability and self-control has higher requirements. Therefore, the mobile learning must develop appropriate self-learning teaching strategies to stimulate students' interest in learning and creativity, improve students' self-learning ability of students to learn in a positive good condition. In task-driven basis, students use mobile devices, access to information, carry out independent learning and cooperative learning groups, discussions and exchange in order to achieve the task solved by group, summarize share tasks in the process and learning evaluation. To better illustrate our approach, we take "Practical English", the first volume of the second unit Food, for example. Mobile learning environment for learner selflearning ability and self-regulatory capacity are higher, in order to obtain better learning results, we designed this unit with topics related to the task: Make a comparison between Chinese food culture and Western food culture. Distributed to students through the micro-channel group, we can give students clear mission requirements. Around the task, the students can timely access to data-related tasks through the use of mobile phones and other mobile devices, in accordance with their own wishes to choose the right way to learn self-learning, at the same time by means of microchannel group, through timely cooperative learning, they can enhance students' sense of belonging.

Self-learning and cooperative learning approach combining not only provide each student the opportunity to learn and solve problems independently, but also provide an opportunity for students to discuss cooperation. Queries and problems related information can also be discussed between the micro-channel group members through the help of a mobile terminal device and to form a more complete answer to the rich. For students, to discuss the process of communication can also be real-time management of teachers and give some guidance to students. In the next class session, teachers must first invite the group to show the use of multimedia equipment to help classmates find out about the differences between Chinese and Western food culture of information, including images, text, video, audio, etc., after which the students were enthusiastic about class discussions. Finally, the teacher lectures and courseware demonstrate the use of a combination of sums up the main content of the lesson. The students have a comprehensive and detailed understanding on the difference between Chinese and Western food culture. After learning of this topic, the teacher will demonstrate the outstanding achievements of students in the air classroom for students to continue to learn and digest. Students and teachers can communicate anytime, anywhere and teachers can use the micro-channel. The class who did not understand the content can always ask the teacher. Teachers can also arrange answering questions based on their own time and taking into account individual differences of students. To better understand Western culture, teachers also uploaded some videos, text information to air classroom. Students can expand online viewing anytime, anywhere.

\section{The Practice OF MobILE LANGUAGE LEARNING IN COLLEGE ENGLISH TEACHING}

\section{A. Preparing for the class}

Even with advanced teaching equipment and tools, classroom still has an orderly, harmonious atmosphere. But the classroom cannot be the classroom for teachers. From modern educational point of view: the classroom should be student-centered, teacher-led. In other words, in the ideal classroom, teachers are in a reasonable and effective macrocontrol, students can play very well in an autonomous nervous and relaxed atmosphere. English is a language. College English class is a required course for college students. The purpose of the course is to improve students' English language proficiency and practice. In "New Horizon College English (Speaking Course)" (second edition), for example, the course fully implement the "course requirements" spirit, make full use of modern information technology, students improve English language proficiency, especially in listening and speaking ability. Someone said: "If we want students to learn the language, we should make them use the language in real life, so receptive skills and productive skills training in textbooks should be like that together organically in life." "Listening and speaking course provides textbooks, CD-ROM, network three kinds of carriers at the same time, its content consolidate and supplement each other. CD's vivid layout and design is mainly for students in extracurricular self-study courses. They are also available on the teacher's presentation. Students change the CD format, or find related content, enter MP4, MP5, cell phone or other mobile device, anytime, anywhere learning for course preparation according to their actual needs and interests.

Institute of Educational Technology published a paper, which introduces the research they use handheld machine learning in primary schools with communicative mobile English learning. They designed a self-learning, family learning and teaching school in three models and experimental data demonstrate the effectiveness of teaching mode. Finally, they found that the future of mobile language learning made the following expectations: to improve the 
quality of learning resources, the improvement of learner support and services should enhance interaction among students, as well as improve the cost of the device. This is a mobile language learning papers domestic, first paper published in the international arena, after mobile language learning in college English teaching, it raises great inspiration and reference value. Still "New Horizon College English (Speaking Course)" (second edition), for example, in addition to supporting CD, it also offers online courses. Online courses are more flexible and interactive. Students can learn the process according to the teachers and teaching schedule set, complete the exercises self-learning part according to their own needs, using pronunciation assistant, spoken dialogue, listening skills training and other learning tools to continuously improve learning strategies, or they can listen and enjoy online audio and video data after school. In addition, the online course also provides notification about class, collaboration and communication, test and evaluation functions such as teaching to help students adjust to independent learning model to improve the self-planning, self-monitoring capability, independent and collaborative learning. Currently, some universities are underway about moving language learning research and practical application (especially in extracurricular autonomous learning) in college English teaching of the subject, the domestic educational technology professional at several universities have mobile learning English Master's thesis. The thesis proved that mobile language learning applications can effectively improve English teaching, especially extracurricular autonomous learning efficiency. But the need for further research in this field is comprehensive and refined.

"College English Curriculum Requirements," pointed out: "Change is not only changes in teaching mode, teaching methods and means, but the changes in teaching philosophy ...... We should pay more attention to culture change, teaching thinking and practice language skills and the practical application of self-learning ability is to train students to transform lifelong learning capabilities oriented lifelong education "to develop the habit of lifelong learning English, first of all, we should meet the needs of learners; secondly, we should ensure that learner motivation; finally, learning content helps learners learn and practice appropriate scene. For the above factors, the first mobile language learning should occur in the learner's leisure time, such as waiting time. According to the needs of learners, mobile language learning design should take full account of the time that the learner can be used to participate in mobile learning time, language materials should be designed for mobile devices, through providing "short (30 seconds to 10 minutes) learning modules" to the use of mobile learners with 'highly flaky' attention. Secondly, to provide personalized content is an important factor to ensure the learner motivation, some mobile language learning system have been using intelligent means to achieve the content providing personalization. As language learning content for the future of mobile becomes richer and richer, individuation can be a more challenging research topic. Finally, to achieve successful language learning, learning in the classroom is not enough, you need a lot of extra-curricular activities to supplement learning or acquisition, language learning community for learners in the appropriate language and practicing a scene plays an important role. Therefore, strengthening the link between learning community of learners and technology will become an important field of mobile language learning research.

\section{CONCLUSIONS}

Future challenges language education facing is how language learning theory organically combines with mobile technology to find the right way to ensure a high degree of situational language learning, personalization, collaboration, continuous learning even realizing lifelong learning. In other words, the challenge is how to achieve true learner-centered and give full play to the advantages of learning technology. For college English teaching, the English teachers must first clear the current form of education and requirements, change roles, from the traditional language imparting knowledge into students to learning English guide. Also, due to the limitation of textbooks and lessons, it is difficult for objectives of making teachers and students face to face to classroom learning to meet the needs of teaching and learning. Therefore, more and more resources and guidance should be developed for the use of self-learning and selfadded mobile language communities learning methods. Of course, in order to get the mobile language learning in college English teaching rational and efficient applications to be successful, to make college students learning English as natural as learning the mother tongue, it also requires us to further the exploration and practice.

\section{References}

[1] Yu Min. College English Mobile Learning Situation and Countermeasures [D]. Jiangxi Normal University, 2012.

[2] Wang Wei. College English Mobile Learning System Model [D] Northeast Normal University, 2011.

[3] Cui Yuhang. Empirical Study of English Vocabulary Mobile Learning [D]. Yan'an University, 2014.

[4] Hu Shun. Research of College English Mobile Learning Systems [J] Science and Technology Information, 2010,36: 192-194.

[5] Guan Li Yan. Study of Mobile Learning Mode of College English Teaching [J]. Keyuan Today, 2008,06: 271.

[6] Bao Wei. Survey of English Learners' Mobile Learning and Mobile Learning Concept Condition [J]. Liaoning Provincial College of Communications, 2012,04: 66-68.

[7] Jiang Dandan. Mobile Learning and Its Application in School Education [D]. Shandong Normal University, 2008. 